Article - Human and Animal Health

\title{
Electrochemical DNA Biosensor for Mycobacterium leprae Identification
}

\author{
André Santiago Afonso ${ }^{1 *}$ \\ https://orcid.org/ 0000-0002-6741-3112 \\ João Marcos Madurro² \\ https://orcid.org/ 0000-0002-2304-4482
}

\section{Ana Graci Brito-Madurro ${ }^{3}$ \\ https://orcid.org/ 0000-0003-3698-9845}

${ }^{1}$ Federal University of Jequitinhonha and Mucuri Valleys, Institute of Science, Engineering, and Technology, Teófilo Otoni, Minas Gerais, Brazil; ${ }^{2}$ Federal University of Uberlândia, Institute of Chemistry, Uberlândia, Minas Gerais, Brazil; ${ }^{3}$ Federal University of Uberlândia, Institute of Genetics and Biochemistry, Uberlândia, Minas Gerais, Brazil.

Editor-in-Chief: Alexandre Rasi Aoki

Associate Editor: Daniel Fernandes

Received: 2021.01.20; Accepted: 2021.05.07.

*Correspondence: andre.afonso@ufvjm.edu.br; Tel.: 5533 3529-2700 (A.S.A.).

\section{HIGHLIGHTS}

- Leprosy is a neglected tropical disease.

- Poly(4-aminophenol) was a good platform for immobilization of DNA.

- The methylene blue was an appropriate hybridization indicator in this electrochemical DNA biosensor.

\begin{abstract}
Nowadays, a prompt and reliable diagnosis is one of the most critical measures for leprosy control. The current diagnostic is based on clinical exams by a health care professional, and it may not recognize early signs of the disease. Therefore, other leprosy diagnosis methods are needed that are sensitive, disease-specific, and easy to deliver to the end-user. This study describes the construction of an electrochemical DNA biosensor to detect PCR products of Mycobacterium leprae using methylene blue as an indicator of the hybridization. The capture probe was immobilized on the graphite electrode modified with poly(4-aminophenol). The electrode surface was morphologically characterized by atomic force microscopy. Linear voltammetry was used to monitor the concentration of methylene blue on the DNA biosensor, which indicated a limit detection of $1 \times 10^{-10} \mathrm{~mol} / \mathrm{L}$. The biosensor showed selective when placed to hybridize with a non-complementary sequence. This study suggests that the electrochemical DNA biosensor developed is promising for detecting DNA of Mycobacterium leprae.
\end{abstract}

Keywords: Poly(4-aminophenol); DNA biosensor; Methylene blue; Mycobacterium leprae.

\section{INTRODUCTION}

Leprosy is a contagious and chronic systemic granulomatous human disease caused by Mycobacterium leprae that primarily affects the cooler body areas as skin and peripheral nerves. Most cases are seen in 
developing countries, although the incidence rate has decreased in most countries for the past 20 years. The disease is still an important cause of morbidity with consequent severe and permanent injuries and mutilations. There were 202,162 new cases detected of leprosy in the world in 2019.[1, 2]

A prompt and reliable diagnosis is one of the most critical measures for leprosy control. Clinical evaluation as dermatologic and neurologic examination, microscopic examination of a slit-skin smear are for diagnosis of leprosy generally sufficient for most cases. However, almost $65 \%$ of all leprosy patients are smear-negative, and untrained health workers may not be efficient in recognizing early signs of the disease [3]. Therefore, there is a need for other leprosy diagnosis methods that are sensitive, disease-specific, userfriendly, quick, reliable, and easy to deliver to the end-user. Nowadays, serological tests[4] and molecular probes [5] have shown a potential for detecting and identifying Mycobacterium leprae in patients, but these methods suffer from limited sensitivity to controversial results. Other recent techniques are arising and may revolutionize diagnostic methods, such as biosensor technologies.

Methods to pathogens detection of clinical interest, based on the analysis of specific DNA sequences as biorecognition elements, have stimulated DNA biosensors development [6]. A DNA biosensor consists of a single-stranded (ssDNA) immobilized on the transducer surface to recognize its complementary sequence. The double-stranded formed on the electrode surface is known as a hybrid (dsDNA), and this event is converted to the analytical signal transducer[7]. DNA biosensors design employing electrochemical transducers presents advantages in analytical science due to high sensitivity, short response time, easy-touse, and low cost[6,7]. The electrochemical detections of DNA are divided into two major groups: label-free and labeled. The first, the DNA biosensor does not rely on the additional signal molecule but only on the physical proprieties of the ssDNA or dsDNA on the electrode surface[8,9,10,11]. In labeled DNA biosensors, the electrochemical response depends on an active redox marker called the hybridization indicator, which changes its concentration upon DNA hybridization. [12]. The most common are dyes and complex metals that interact with DNA.

The modification of the electrode surfaces can increase the efficiency and applicability of electrochemical sensors[13]. The modification of surfaces with polymer films has been used to develop biosensors to protect the surface of the electrodes of impurities, block interfering, incorporate mediators, and provide biocompatibility. It is a promising strategy for immobilization of DNA probes in the development of DNA biosensors. Electropolymerization studies indicate that monomers containing aromatic groups bonded to oxygen atoms are easier to polymerize, providing reproducibility and mechanical resistance of the film[14]. The use of aminophenols in the preparation of electrodes modified with polymer films can be applied in biosensors development because this molecule presents two functional groups $\left(-\mathrm{NH}_{2}\right.$ and $\left.-\mathrm{OH}\right)$, both appropriate for immobilization of biomolecules[15].

Taj et al. (1992) reported for the first time the formation of the poly(4-aminophenol) in platinum electrode, using cyclic voltammetry as the technique for electropolymerization [16]. Since then, other groups have shown interest in production to elucidate these film structures and applications [17,18,19,20]. Madurro and co-workers showed the formation of poly(4-aminophenol) on graphite electrodes at different $\mathrm{pH}$ values. Analyses indicated that films prepared in an acid medium promote charge transfer. Moreover, films prepared in a basic medium passivate the electrode, hindering the charge transfer[21]. Brito-Madurro et al. (2007) showed that graphite electrodes modified with poly(4-aminophenol) are adequate for immobilization of biomolecules (guanosine triphosphate and adenosine triphosphate). The signal amplitude for detecting these bases was twenty-four times more significant than the bare graphite electrode[22]. Madurro and co-workers conducted studies showing that electrodes modified with poly(4-aminophenol) efficiently immobilize nucleotides or oligonucleotides. All four bases (adenine, guanine, cytosine, and thymine) can be determined simultaneously by voltammetry[15,18].

Herein, an electrochemical DNA biosensor for detecting Mycobacterium leprae using methylene blue as an indicator of the hybridization was reported. The probe of the genosensor was a single-stranded DNA (78pb DNA fragment), PCR amplified from the RLEP3 region, which is a specific sequence of the Mycobacterium leprae genomic DNA. The capture probe was immobilized on the graphite electrode modified with poly(4aminophenol), providing a recognition surface for hybridization with the DNA target. To our knowledge, this is the first report in the literature showing the detection in modified electrodes of specific DNA sequence of Mycobacterium leprae using methylene blue as a hybridization indicator.

\section{MATERIAL AND METHODS}

All electrochemical experiments were in a three-compartment electrochemical cell containing a graphite working electrode of $6 \mathrm{~mm}$ diameter, cut from a graphite rod (99.9995\%, Alfa Aesar), platinum as a counter 
electrode, and a saturated calomel electrode (SCE) as a reference electrode, respectively, connected to a potentiostat $\mathrm{CH}$ Instruments, model $760 \mathrm{C}$. Ultra-high purity water (Master System, Gehaka, Brazil) was used for the preparation of the 4-aminophenol (Acros Organics) solutions. Monomer solutions $\left(2.5 \times 10^{-3} \mathrm{~mol}^{-\mathrm{L}^{-1}}\right)$ were prepared in $0.5 \mathrm{~mol}^{-1} \mathrm{~L}^{-1} \mathrm{HClO}_{4}$ solution, immediately before use.

The polymerase chain reaction for gene-specific of Mycobacterium leprae was performed in a final volume of $25 \mu \mathrm{L}$, containing $200 \mu \mathrm{mol} \cdot \mathrm{L}^{-1}$ of dNTPs, $1.6 \mathrm{mmol} \cdot \mathrm{L}^{-1}$ of $\mathrm{MgCl}_{2}, 1$ X PCR buffer (Tris- $\mathrm{HCl} 10 \mathrm{mM}$, pH 9.0), 10 pmol of primers sense: 5'-GCA GTG GGC AGT AGG GTG AT-3' and anti-sense: 5'-CAC CGA AAG CTC ATG GCC AC-3', 1 U of Platinum Taq, $400 \mathrm{ng}$ of genomic DNA, in $0.2 \mathrm{~mL}$ thin-walled polypropylene tubes. All reagents to this reaction were obtained from Invitrogen Life Technology. Polymerase chain reaction (PCR) was performed on a standard Perkin Elmer 9600 cycles (Perkin Elmer, Warrington). The PCR amplification was performed in the following conditions: $95^{\circ} \mathrm{C}(1$ minute $), 58^{\circ} \mathrm{C}\left(20\right.$ seconds), $72^{\circ} \mathrm{C}(30$ seconds) - 36 cycles, $72^{\circ} \mathrm{C}$ (10 minutes), $4^{\circ} \mathrm{C}$ (10 minutes). Amplicon detection was done by electrophoresis of the end products in a $0.8 \%$ agarose gel stained with ethidium bromide and visualized under ultraviolet light. The size of the PCR product was $78 \mathrm{bp}$. The fragments were separated with agarose gel electrophoresis to obtain $100 \mathrm{~mL}$ PCR product. The dsDNA or PCR product concentration was measured through the ultraviolet absorption at $260 \mathrm{~nm}\left(\varepsilon=6600 \mathrm{~L} \mathrm{~mol}^{-1} \mathrm{~cm}^{-1}\right)$. The amplification product without further purification gave an A260/A280 ratio of 1.82; thus, the DNA was pure enough. The product obtained from PCR sequenced below was used as a capture probe and target complementary.

\section{5’-GCAGGCGTGAGTGTGAGGATAGTTGTTAGCGCCGCGGGGTAGGGGCGTTTTAG TGTGCATGTCATGGCCTTGAGGTGT- 3’}

\section{3'-CGTCCGCACTCACACTCCTATCAACAATCGCGGCGCCCCATCCCCGCAAAATC ACACGTACAGTACGGGAACTCCACT- 5}

The following sequence was used as a target non-complementary.

\section{5'-CACGTAAGCATGTCGGTGGTGGATGCTGCTTGGTCTACATGTTGATGATGCC AGGGGCTGGGCACCTGGGCTGTGCTGAAGGCGATATC- 3’}

The phosphate buffer solution was prepared at $\mathrm{pH}$ 7.4. Buffer solution for DNA immobilization (TE buffer) was prepared with Tris- $\mathrm{HCl} 10 \times 10^{-3} \mathrm{~mol} \cdot \mathrm{L}^{-1}, \mathrm{pH} 8.0$, containing EDTA $1 \times 10^{-3} \mathrm{~mol} \mathrm{~L}^{-1}$. For DNA detection, methylene blue $20 \times 10^{-3} \mathrm{~mol} \mathrm{~L}^{-1}$ in $\mathrm{NaCl} 20 \times 10^{-3} \mathrm{~mol} \mathrm{~L}^{-1}$ was added to the electrode surface. All reagents were used without further purification, and the experiments were conducted at room temperature $\left(25 \pm 1^{\circ} \mathrm{C}\right)$.

Film morphology in the absence or presence of biomolecules was assessed by atomic force microscopy (AFM) (Nanoscope IIla, Digital Instruments).

Before electropolymerization, the bare graphite electrode was mechanically polished with alumina $(0.3$ $\mu \mathrm{m})$ slurry, ultrasonicated, washed with deionized water, and dried in the air. The 4-Aminophenol solution was deoxygenated through bubbling with $\mathrm{N}_{2}$ before electropolymerization. The monomer 4-aminophenol was electropolymerized on a graphite electrode through continuous potential cycling, according to Franco et al., 2008[15]. After electropolymerization, the modified electrode was rinsed with deionized water to remove the unreacted monomer.

The thermal stability of poly(4-aminophenol) was evaluated as a function of thermal treatment. The electrode was maintained at a temperature of $98 \pm 1{ }^{\circ} \mathrm{C}$ for 2 hours and, in every 5 minutes, submitted at potential scans in $0.5 \mathrm{~mol} \cdot \mathrm{L}^{-1} \mathrm{HClO}_{4}$ solution, between $+0.30 \mathrm{~V}$ to $+0.55 \mathrm{~V}$ vs. SCE at $100 \mathrm{mVs}^{-1}$. A control experiment was performed using an electrode modified with a polymer film without thermal treatment.

For immobilization and hybridization of the PCR product (RLEP3), a pre-conditioning and polarization of the surface of the graphite electrode modified with poly (4-aminophenol) was conducted[23]. It was subjected to successive sweeps of potential from 0 to $+0.8 \mathrm{~V}$ vs. SCE, in phosphate buffer solution until the voltammograms remain constant. RLEP3 was denatured at $98^{\circ} \mathrm{C}$ for 5 minutes.

Scheme 1 represents the electrochemical DNA biosensor using a hybridization indicator to identify Mycobacterium leprae. Initially, $15 \mu \mathrm{L}$ of the denatured sample $\left(3.93 \times 10^{-8} \mathrm{~mol}^{-\mathrm{L}^{-1}}\right.$ in TE) was added onto the surface of the modified electrode. The electrode was kept at $98^{\circ} \mathrm{C}$ for 3 minutes to assure the maintenance of ssDNA, washed with phosphate buffer solution ( $\mathrm{pH}$ 7.4) for 5 seconds, and dried with ultra-pure $\mathrm{N}_{2} .15 \mu \mathrm{L}$ of the target complementary or non-complementary DNA in TE buffer were added onto the surface of the modified electrode containing the probe. The hybridization was carried out at $42^{\circ} \mathrm{C}$ for $3 \mathrm{~min}$. Methylene blue 
was added to the electrode surface. It was kept for 5 minutes, and after that, the modified electrode was washed with phosphate buffer. Linear voltammetry was the technique used for electrochemical detection of the DNA in phosphate buffer solution ( $\mathrm{pH} 7.4)$.

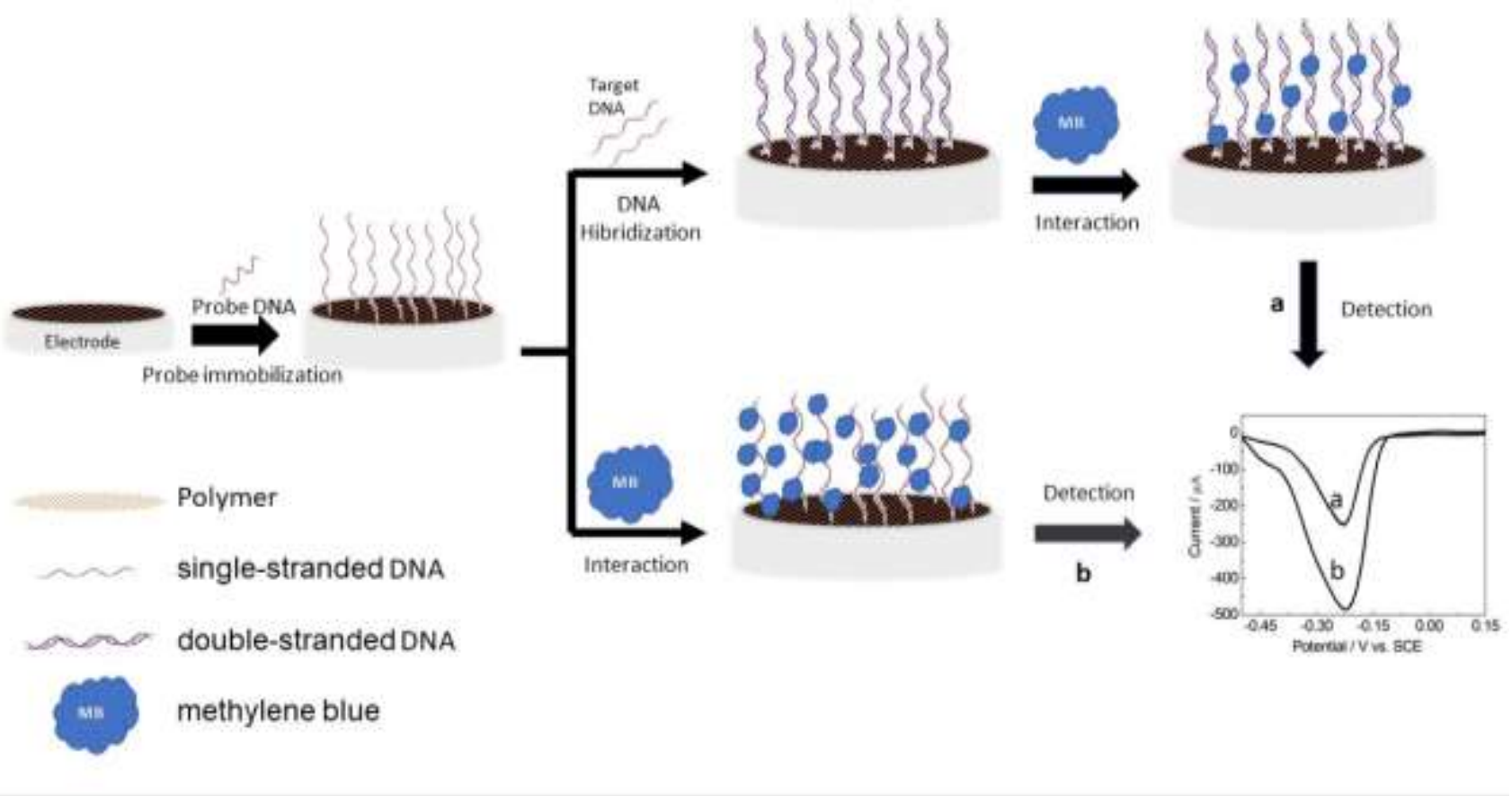

Scheme 1. Schematic illustration of the electrochemical DNA biosensor for the identification of Mycobacterium leprae

\section{RESULTS AND DISCUSSION}

\section{Evaluation of thermal stability of the poly 4-aminophenol modified electrode}

The poly(4- aminophenol) thermal stability was carried out to evaluate the method's feasibility for RLEP3 immobilization. In this condition, the physics and chemistry properties of the film should be maintained. According to Figure 1, the electrical charge of oxidation waves of the electrode modified without thermal treatment maintained stable after 25 potential scans, demonstrating its electrochemical stability in these conditions. The electrode modified with polymer film submitted to thermal treatment for 20 minutes maintained about $70 \%$ of the electrical charge of the first oxidation wave. This result suggests that poly(4aminophenol) had a low loss of conjugation, maintaining the electroactivity and doping and dedoping of ions into poly(4-aminophenol) films[24].

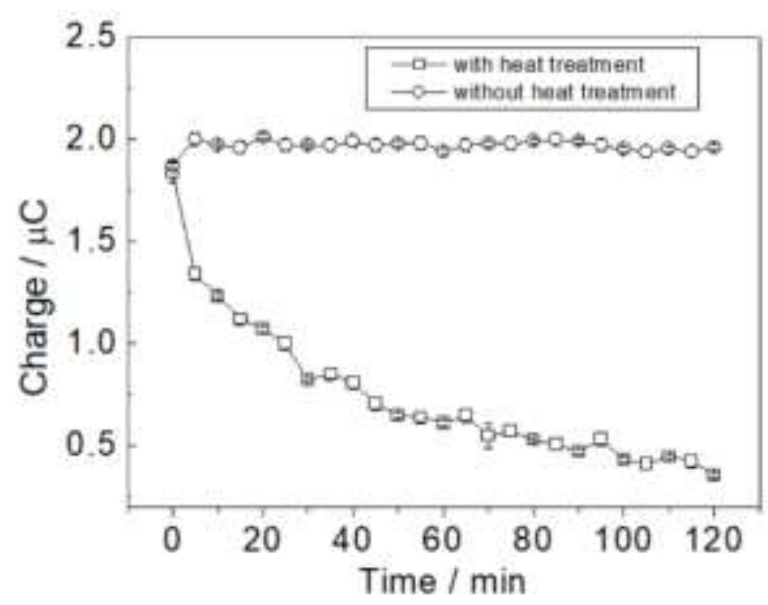

Figure 1. The electrical charge of the oxidation wave of poly(4-aminophenol) in $0.5 \mathrm{~mol} \cdot \mathrm{L}^{-1} \mathrm{HClO}_{4}$. The electrode was maintained at a temperature of $98 \pm 1^{\circ} \mathrm{C}$ for 5 min over 2 hours. 


\section{Analysis of atomic force microscopy}

Mode AFM images were used to demonstrate the surface modification without DNA, after immobilization of SsDNA, and after hybridization event with the complementary target. As shown in figure 2, the roughness value obtained for the graphite electrode modified with poly(4-aminophenol), poly(4-aminophenol)/ssDNA, poly(4-aminophenol)/dsDNA were $639.9 \mathrm{~nm}, 367.3 \mathrm{~nm}, 504.64 \mathrm{~nm}$, respectively. The immobilization of ssDNA on the graphite electrode modified with poly(4-aminophenol) causes a decrease in the roughness of the surface and differences in height and shape of the clusters, figure $2 \mathrm{~B}$. According to the literature, that occurs due to the DNA probe penetrates in conducting polymer chains as described by poly(4aminothiophenol) and polypyrrole[25]. This observation confirms the success of ssDNA immobilization on the surface of the graphite electrode modified. Figure $2 \mathrm{C}$ indicates an increase in roughness and the presence of larger clusters after the hybridization event. Following the literature, double-stranded DNA molecules are more elongated and inflexible than single-stranded DNA molecules, resulting in larger structures[26]. It could explain the increase of roughness surface. From these results, we can suggest that a hybridization event occurs on the electrode surface.
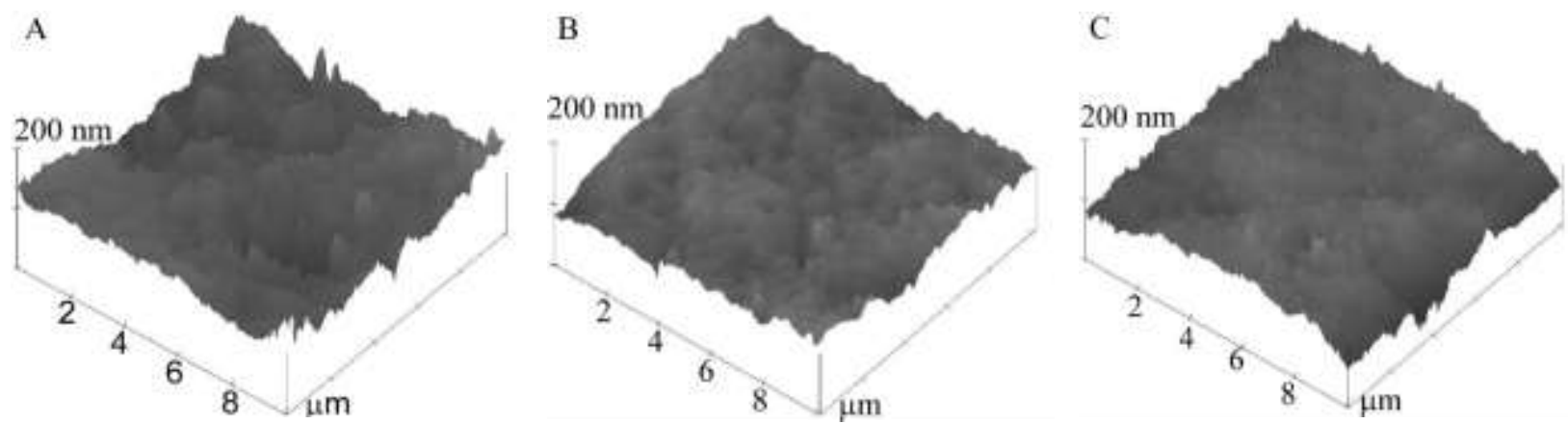

Figure 2. AFM topographical images of modified graphite electrode with poly(4-aminophenol): (a) without biomolecules; after immobilization and hybridization with biomolecules: (b) RLEP3, ssDNA, before hybridization; (c) RLEP3, dsDNA, after hybridization.

\section{Detection of PCR product using methylene blue}

The methylene blue $(\mathrm{MB})$ is an organic dye used as a hybridization indicator in electrochemical DNA biosensors that interacts differently with ssDNA and dsDNA[27,28,29]. Fig. 3A shows linear voltammograms of $\mathrm{MB}$ on a graphite electrode modified with poly(4-aminophenol) containing SsDNA before and after hybridization assay, with complementary target at concentration $3.93 \times 10^{-8}, 3.93 \times 10^{-9}, 3.93 \times 10^{-10}, 3.93 \times$ $10^{-11}$ and $3.93 \times 10^{-12} \mathrm{~mol} / \mathrm{L}$. An obvious decrease in the voltammetric peak at $-0.22 \mathrm{~V}$ is observed for the MB with increased concentration of the complementary target. The decrease in the magnitude voltammetric peak occurs due to lesser interaction of MB with guanine bases because the accessibility of unbounded guanine bases is greater in ssDNA than in dsDNA[30, 31]. A linear relationship of the current concentration of the complementary target was observed, as shown in Fig. $3 \mathrm{~B}$. The linear regression obtained was $\mathrm{I}_{(\mu \mathrm{A})}=$ $-56.62 \times \log ([s s D N A])-156.8$ for three independent experiments with $R^{2} 0.90$. The detection limit for the complementary target was $1 \times 10^{-10} \mathrm{~mol} / \mathrm{L}$.
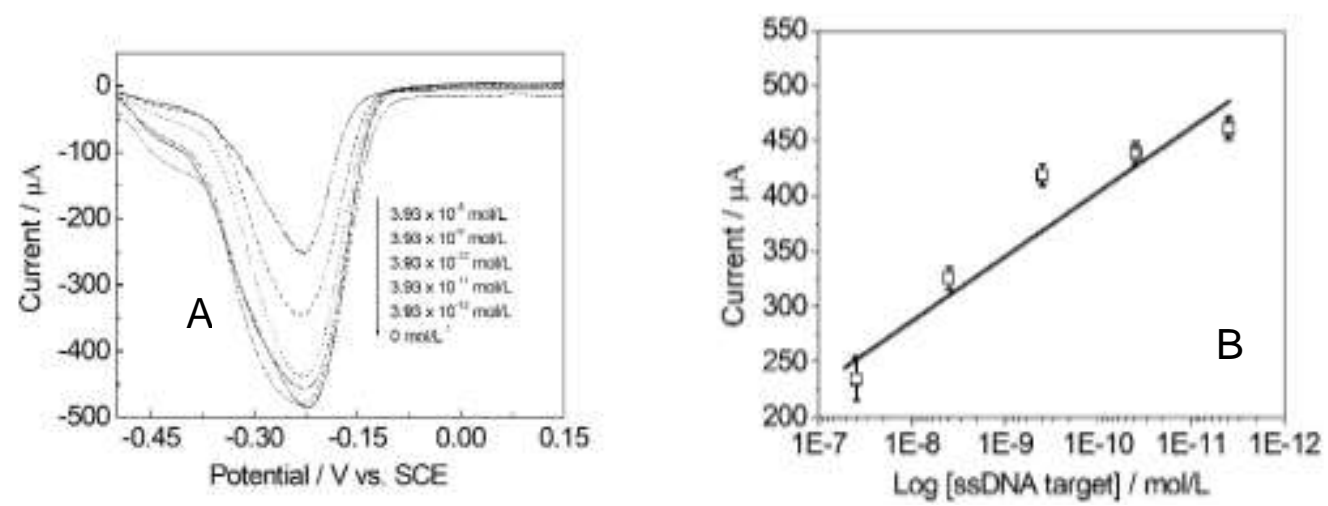

Figure 3. (A) Linear voltammograms of $M B$ on a graphite electrode modified with poly(4-aminophenol) containing ssDNA before and after hybridization assay, with complementary target at concentration $3.93 \times 10^{-8}, 3.93 \times 10^{-9}$, 3.93 x 10-10, 
$3.93 \times 10^{-11}$ and $3.93 \times 10^{-12} \mathrm{~mol} / \mathrm{L}$ in phosphate buffer, $\mathrm{pH}$ 7.4. (B) The plot of reduction current of methylene blue vs. logarithmic concentration of the ssDNA target.

In the selectivity assay, Figure 4 shows a graphite electrode modified with poly(4-aminophenol) containing ssDNA placed to hybridize with a complementary and non-complementary sequence, both in the concentration of $3.93 \times 10^{-8} \mathrm{~mol} / \mathrm{L}$. The magnitude of the peak reflects the extent of the interaction of $\mathrm{MB}$ with ssDNA. When the DNA biosensor was placed to hybridize with a non-complementary sequence, the peak current of reduction $\mathrm{MB}$ did not change compared to the peak current reduction of $\mathrm{MB}$ for poly(4aminophenol) containing ssDNA. This result suggests selectivity to the system studied.

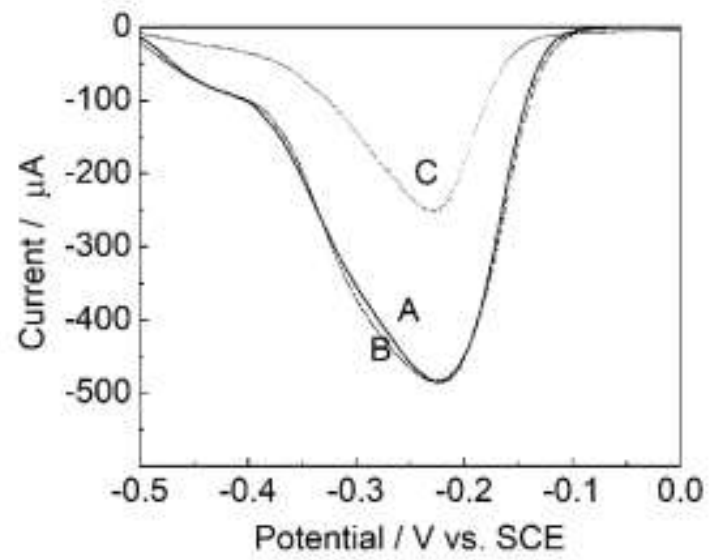

Figure 4. Linear voltammograms of DNA biosensors with complementary $\left(3.93 \times 10^{-8} \mathrm{~mol} / \mathrm{L}\right)$ and non-complementary targets $\left(3.93 \times 10^{-8} \mathrm{~mol} / \mathrm{L}\right)$ using the reduction signal of $\mathrm{MB}$, supporting electrolyte: phosphate buffer, $\mathrm{pH}$ 7.4. Before hybridization (A), after hybridization with non-complementary sequence $(B)$ after hybridization with complementary sequence $(C)$.

\section{CONCLUSION}

This study reports the construction of an electrochemical DNA biosensor to detect PCR products of Mycobacterium leprae. The graphite electrode modified with poly(4-aminophenol) proved to be a promising platform for DNA immobilization. Furthermore, it exhibited good thermal stability after 20 min incubation at $98 \stackrel{\circ}{\circ}$, maintaining its electroactivity. The DNA biosensor showed a low limit detection and selectivity when placed to hybridize with a non-complementary sequence. The electrochemical DNA sensor offers good sensitivity and amenable to miniaturization. This study suggests that electrochemical DNA biosensor developed are promising for detecting DNA of Mycobacterium leprae, but it is necessary to continue research with DNA biosensor to develop its protocol with real samples of Mycobacterium leprae.

Acknowledgments: We thank the Institute of Science, Engineering, and Technology of the Federal University of Jequitinhonha and Mucuri Valleys and the Federal University of Uberlândia for support of this work.

Conflicts of Interest: The authors declare no conflict of interest.

\section{REFERENCES}

1. McEwen MW, Patel TS. Hansen Disease (Leprosy). Mayo Clin Proc. 2020 Nov;95(11):2555-6.

2. Steinmann P, Dusenbury C, Addiss D, Mirza F, Smith WCS. A comprehensive research agenda for zero leprosy. Infect Dis Poverty. 2020 Nov;9(1).

3. Maymone MBC, Laughter M, Venkatesh S, Dacso MM, Rao PN, Stryjewska BM, et al. Leprosy: Clinical aspects and diagnostic techniques. J Am Acad Dermatol. 2020 Jul;83(1):1-14.

4. World Health Organization. Regional Office for South-East A. Guidelines for the diagnosis, treatment and prevention of leprosy [Lignes directrices pour le diagnostic, le traitement et la prévention de la lèpre] [Directrices para el diagnóstico, tratamiento y prevención de la lepra] [Diretrizes para o diagnóstico, tratamento e prevenção da hanseníase]. New Delhi: World Health Organization. Regional Office for South-East Asia 2018.

5. Barbieri RR, Manta FSN, Moreira SJM, Sales AM, Nery JAC, Nascimento LPR, et al. Quantitative polymerase chain reaction in paucibacillary leprosy diagnosis: A follow-up study. PLoS Neglected Trop Dis. 2019 Mar;13(3).

6. Du Y, Dong SJ. Nucleic Acid Biosensors: Recent Advances and Perspectives. Anal Chem. 2017 Jan;89(1):189215. 
7. Kara P, Kerman K, Ozkan D, Meric B, Erdem A, Ozkan Z, et al. Electrochemical genosensor for the detection of interaction between methylene blue and DNA. Electrochem Commun. 2002 Sep;4(9):705-9.

8. Liu BQ, Zhang B, Chen GN, Yang HH, Tang DP. Proximity Ligation Assay with Three-Way Junction-Induced Rolling Circle Amplification for Ultrasensitive Electronic Monitoring of Concanavalin A. Anal Chem. 2014 Aug;86(15):777381.

9. Xu MD, Zhuang JY, Chen X, Chen GA, Tang DP. A difunctional DNA-AuNP dendrimer coupling DNAzyme with intercalators for femtomolar detection of nucleic acids. Chem Commun. 2013;49(66):7304-6.

10. Zhang J, Tang Y, Teng LM, Lu MH, Tang DP. Low-cost and highly efficient DNA biosensor for heavy metal ion using specific DNAzyme-modified microplate and portable glucometer-based detection mode. Biosens Bioelectron. 2015 Jun;68:232-8.

11. Cui L, Hu J, Wang M, Li CC, Zhang CY. Label-Free and Immobilization-Free Electrochemical Magnetobiosensor for Sensitive Detection of 5-Hydroxymethylcytosine in Genomic DNA. Anal Chem. 2019 Jan;91(2):1232-6.

12. Cui L, Hu J, Li CC, Wang CM, Zhang CY. An electrochemical biosensor based on the enhanced quasi-reversible redox signal of prussian blue generated by self-sacrificial label of iron metal-organic framework. Biosens Bioelectron. 2018 Dec;122:168-74.

13. Zamani FG, Moulahoum H, Ak M, Demirkol DO, Timur S. Current trends in the development of conducting polymersbased biosensors. Trac-Trends Anal Chem. 2019 Sep;118:264-76.

14. Oliveira RML, Vieira SN, Alves HC, Franca EG, Franco DL, Ferreira LF, et al. Electrochemical and morphological studies of an electroactive material derived from 3-hydroxyphenylacetic acid: a new matrix for oligonucleotide hybridization. J Mater Sci. 2010 Jan;45(2):475-82.

15. Franco DL, Afonso AS, Vieira SN, Ferreira LF, Gonçalves RA, Brito-Madurro AG, et al. Electropolymerization of 3aminophenol on carbon graphite surface: Electric and morphologic properties. Mater Chem Phys. 2008 Feb 15;107(2-3):404-9.

16. Taj S, Ahmed MF, Sankarapapavinasam S. Poly(Para-Aminophenol) - A new soluble, electroactive conducting polymer. J Electroanal Chem.1992 Oct 26;338(1-2):347-52.

17. Salavagione HJ, Arias J, Garces P, Morallon E, Barbero C, Vazquez JL. Spectroelectrochemical study of the oxidation of aminophenols on platinum electrode in acid medium. J Electroanal Chem. 2004 Apr;565(2):375-83.

18. Ferreira LF, Boodts JFC, Brito-Madurro AG, Madurro JM. Gold electrodes modified with poly (4-aminophenol): incorporation of nitrogenated bases and an oligonucleotide. Polym Int. 2008 Apr;57(4):644-50.

19. Caetano L, Costa K, Silva T, Dias L, Rodovalho V, Madurro JM, et al. Use of gold nanoparticles on graphite electrodes functionalized with poly (4-aminophenol) in the development of a bioelectrode for hepatitis B. BMC Proc. 2014 oct;8(4):P57.

20. Segatto MS, Soler FS, Oliveira CAP, Brito-Madurro AG, Madurro JM. Novel electrochemical platform based on copolymer poly(aniline-4-aminophenol) for application in immunosensor for thyroid hormones. J Solid State Electrochem. 2020;24(8):1751-7.

21. Vieira SN, Ferreira LF, Franco DL, Afonso AS, Goncalves RA, Brito-Madurro AG, et al. Electrochemical modification of graphite electrodes with poly(4-aminophenol). Macromol Symp. 2006;245:236-42.

22. Brito-Madurro AG, Ferreira LF, Vieira SN, Ariza RG, Goulart LR, Madurro JM. Immobilization of purine bases on a poly-4-aminophenol matrix. J Mater Sci. 2007 May;42(9):3238-43.

23. Afonso AS, Goulart LR, Goulart IMB, Machado AEH, Madurro JM, Brito-Madurro AG. A Promising Bioelectrode Based on Gene of Mycobacterium leprae Immobilized onto Poly(4-aminophenol). J Appl Polym Sci. 2010 Dec;118(5):2921-8.

24. Baba A, Tian SJ, Stefani F, Xia CJ, Wang ZH, Advincula RC, et al. Electropolymerization and doping/dedoping properties of polyaniline thin films as studied by electrochemical-surface plasmon spectroscopy and by the quartz crystal microbalance. J Electroanal Chem. 2004 Jan;562(1):95-103.

25. Lassalle N, Mailley P, Vieil E, Livache T, Roget A, Correia JP, et al. Electronically conductive polymer grafted with oligonucleotides as electrosensors of DNA - Preliminary study of real time monitoring by in situ techniques. $J$ Electroanal Chem. 2001 Aug;509(1):48-57.

26. Holmberg M, Kühle A, Garnæs J, Boisen A. Hybridisation of short DNA molecules investigated with in situ atomic force microscopy. Ultramicroscopy. 2003 oct;97(1):257-61.

27. Zeng RJ, Su LS, Luo ZB, Zhang LJ, Lu MH, Tang DP. Ultrasensitive and label-free electrochemical aptasensor of kanamycin coupling with hybridization chain reaction and strand-displacement amplification. Anal Chim Acta. 2018 Dec;1038:21-8.

28. Zhou J, Lai WQ, Zhuang JY, Tang J, Tang DP. Nanogold-Functionalized DNAzyme Concatamers with Redox-Active Intercalators for Quadruple Signal Amplification of Electrochemical Immunoassay. Acs Appl Mater Interfaces. 2013 Apr;5(7):2773-81. 
29. Zhuang JY, Tang DP, Lai WQ, Chen GN, Yang HH. Immobilization-Free Programmable Hairpin Probe for Ultrasensitive Electronic Monitoring of Nucleic Acid-Based on a Biphasic Reaction Mode. Anal Chem. 2014 Aug;86(16):8400-7.

30. Erdem A, Kerman K, Meric B, Akarca US, Ozsoz M. Novel hybridization indicator methylene blue for the electrochemical detection of short DNA sequences related to the hepatitis B virus. Anal Chim Acta. 2000 Oct;:422(2):139-49.

31. Guo MD, Li YQ, Guo HX, Wu XQ, Fan LF. Electrochemical detection of short sequences related to the hepatitis $B$ virus using MB on chitosan-modified CPE. Bioelectrochemistry. 2007 May;70(2):245-9.

(C) (7) 8 (5) 2021 by the authors. Submitted for possible open access publication under the terms and
conditions of the Creative Commons Attribution (CC BY NC) license
(https://creativecommons.org/licenses/by-nc/4.0/). 